\title{
Viewpoint: Cardiac implantable electronic devices and magnetic resonance compatibility: was it really necessary?
}

\author{
Richard Sutton ${ }^{1}$ (D) David G. Benditt ${ }^{2}$
}

Received: 6 December 2018 / Accepted: 3 February 2019 / Published online: 22 February 2019

(C) Springer Science+Business Media, LLC, part of Springer Nature 2019

In 2005, Irnich et al. reported in Europace [1] the occurrence of six pacemaker patient deaths during magnetic resonance imaging (MRI). These deaths were identified from files in German institutional medicolegal offices in various cities; it was believed that the deaths were not previously published, and thereby should be considered additional to deaths already known to the medical community at that time [1]. Specifically, the authors found that the deaths had occurred under a variety of MRI circumstances, i.e., four different MRI manufacturers, $0.5-1.5$ Tesla $(\mathrm{T})$ with half the deaths occurring in low induction $(0.5 \mathrm{~T})$ machines. It was notable that all had sinus node dysfunction as an indication for pacing (pacemakers from four different manufacturers), but none was pacemaker-dependent [1]. ECG monitoring was not performed in any patient but ventricular fibrillation was given as the cause of death in three and suspected in two others. The remaining cause of death was not assigned. The authors provided little background information in the way of clinical data regarding the patients or their care.

Although medical device manufacturers were aware of health risks before this time [2-4], the communication by Irnich et al. seems to have been the report that triggered manufacturers, led by Medtronic Inc. (Minneapolis, MN, USA), to initiate steps to modify hardware and software in their cardiac implantable electronic devices (CIEDs) and leads, and thereby make them as safe as possible during MRI.

By 2011, after considerable research, development, and great expenditure, Medtronic completed a randomized controlled clinical trial of a new pacemaker and leads designed

Richard Sutton

r.sutton@imperial.ac.uk

1 National Heart \& Lung Institute, Imperial College, Department of Cardiology, Hammersmith Hospital Campus, Ducane Road, London, UK

2 Arrhythmia Center, University of Minnesota, Minneapolis, MN, USA and built to minimize adverse MRI effects [5]. The trial included 464 patients with the new devices trademarked EnRhythm MRI SureScan ${ }^{\mathrm{TM}}$ and CapSureFix MR 5086 ${ }^{\mathrm{TM}}$ leads. The patients were divided into a group of 258 who were scanned, using $1.5 \mathrm{~T}$, and 206 who were not scanned. All underwent the same measurements chosen to assess potential MRI effects. No significant differences were found in terms of pacing parameters at implant, immediately before and after scanning (or no scanning) up to 4 months, and also there were no differences in complications over these four follow-up months.

Other manufacturers were obliged to follow Medtronic's lead. Approval by the US Food and Drug Administration (FDA) ensued for restricted use of MRI with these devices.

Subsequently, Medtronic's new pacemaker lead, model 5086, proved very stiff in clinical use and there were several reported cardiac perforations with some occurring several weeks after implant [6]. These adverse events prompted Medtronic to submit a previous lead design, model 5076 [7], without the re-engineering embodied in the 5086 MR conditional lead, and ultimately this "legacy" lead received MRconditional labeling. Approximately concurrently, Biotronik (Berlin, Germany) submitted their currently available and unmodified devices for FDA MR-conditional approval which was received, albeit with more restrictions than for Medtronic's devices. The main difference was the area of the body which was permitted to be scanned. For Biotronik, the thorax had to be avoided.

Gradually, all major manufacturers received FDA approval for MR-conditional labeling of implanted devices and leads with varying restrictions. Some, such as St. Jude Medical (now Abbott Labs, Chicago, IL) had gone to considerable engineering lengths to modify their devices and others had made no changes. However, MR imaging of device patients was not immediately accepted by radiologists. The latter was, especially the case in the United States (US) at least, partially due to the lack of 
reimbursement offered for studying CIED patients with non-MRI conditional systems in situ.

During the period 2005-2018, MRI has grown substantially in clinical usage [8]. For example, it is now considered almost impossible to achieve the best results in tumor treatment without multiple MRI examinations. Similar developments have occurred in orthopedics and other specialties.

The growth of MRI importance has put pressure on cardiologists to make their patients as safe as possible in MR environments. One obvious way was to implant only MRconditional devices. However, major impediments to such a policy, include both greater cost of MR-conditional systems and the residual large burden of patients already implanted with non-MR-conditional CIEDs and/or leads, some possibly abandoned. Consequently, despite initial trepidation, physicians were, of necessity, forced to undertake MRI in patients with non-MR-conditional systems. As a result, there is now substantial accumulated clinical experience indicating that such procedures can be undertaken safely (at least with current 1.5 Tesla MR equipment) [7-10]. Further, available guidelines detail the necessary safety measures required for scanning MR-conditional devices [11, 12], and these same techniques have been applied and also extended to include those with non-MR conditional devices [13-17]. For example, in a registry of 1000 patients with non-MRI-conditional CIEDs undergoing MRI examinations in $1.5 \mathrm{~T}$ machines, there were no recorded complications of any sort [13].

Given the apparent outcome of this story, the need for special MR-conditional systems may not have been so great as was initially perceived; consequently, it is reasonable to reexamine the original report of MR-related deaths. In doing so, it is apparent that the 2005 report by Irnich et al. [1] does not stand up well to scrutiny; in brief, it provided too little evidence of the specific circumstances. The reported deaths occurred in private MR radiology practices without ECG monitoring. Thus, although three of six deaths were attributed to ventricular fibrillation, it is impossible to understand the sequence events that took place prior to the death of these patients.

One of us (RS) was the Editor-in-Chief of Europace at the time of the Irnich publication [1] and it may reasonably be asked whether the paper should have been published. However, the editorial attitude at the time was that the potential safety issue was important. Subsequent developments have tended to demonstrate that provided diligent safety measures are taken, patients need not be at great risk in the MR environment even without MR conditional devices.

So were the CIED developments in hardware and software really needed?

In retrospect, we may say that the developments were most likely unnecessary, while stringently applied precautions were always necessary. Nevertheless, benefit has accrued. The engineering contributions should not be discarded as they will undoubtedly contribute to patient safety in the future. On the other hand, practice guidelines should be re-visited to accommodate the possibility that non-MR-conditional devices can be MR scanned safely, and also provide instruction regarding the essential required care; such instruction is lacking in both the HRS document of 2017 [11] and the ESC version of 2013 [12]. The latest US CMS reimbursement decision [18] provides an ample basis for such revision of the guidelines. Further, although radiologists have been kept informed of these changes in recommendations, they often remained reluctant to expose patients with non-MR-conditional CIEDs to imaging, despite the great value such imaging offers. Some of this reluctance was understandably related to the lack of reimbursement in the US, a problem now solved, in general, by changes in reimbursement criteria introduced in April 2018 [18].

Fortunately, radiologists' reluctance is now waning. An important relevant document was released in the UK in August 2018 jointly by the Royal College of Radiologists and the British Cardiovascular Society [19]. In the statement, the invaluable nature of MRI and its superiority over other available tests are stressed. Two developments have recently occurred: MR-conditionality has become the industry's standard, implying that with current CIEDs $>95 \%$ of the implanted patients can undergo MRI following the advised precautions and, secondly, there has been an accumulation of evidence demonstrating that non-MR-conditional CIEDs, "legacy" devices, with appropriate safety measures can also be safely scanned. The joint professional groups believe that CIED patients can no longer be disadvantaged by not receiving indicated MRI. However, a problem remains with device-dependent patients as outlined in the US CMS decision. Further study of MR safety in such patients is still needed.

What precautions are mandatory? MRI must be planned and agreed by cardiologist, radiologist, and patient. On the day of imaging, a suitable cardiology technologist or physician must be available to program the patient's device to the safest available mode, having tested and recorded its pacing parameters. That individual should remain present throughout the study. ECG and oxygen saturation monitoring must be functional for the whole period. The MRI will inevitably adversely impact the ECG, but oxygen saturation monitoring should be unaffected. Finally, the patient needs good verbal communication to the radiologist in order to be able to report symptoms. At the end of the examination, the pacing parameters need to be reassessed and the device reprogrammed to appropriate settings. The team accompanying the patient to the MRI suite must be trained in resuscitation and all required resuscitation equipment must be in immediate proximity. It is recommended that these points be presented as a table in new guidelines and copies could be made into a poster to be displayed in the MRI unit. 
In conclusion, the industry may have over-reacted to poorly documented fatalities related to MRI, but the end result has led to beneficial advances in CIED and lead design. At the same time, MRI teams have developed protocols that now permit "legacy" device patients to receive safely the important advantages of MRI, while new technology reduces CIED-induced artifacts during scanning [14]. With appropriate monitoring and device programming, given the potential for MRI benefit, even pacemaker-dependent patients should now be candidates for MRI.

\section{Compliance with ethical standards}

Conflict of interest RS is a consultant to Medtronic Inc. and a member of the Speakers' Bureau of Abbott Labs. He is also a shareholder in AstraZeneca, Boston Scientific Inc., and Edwards Lifesciences. DGB is a consultant to Medtronic Inc. and Abbott Labs and receives support from Dr. Earl E Bakken Family for Heart-Brain Research.

Publisher's note Springer Nature remains neutral with regard to jurisdictional claims in published maps and institutional affiliations.

\section{References}

1. Irnich W, Irnich B, Bartsch C, Stertmann WA, Gufler H, Weiler G. Do we need pacemakers resistant to magnetic resonance imaging? Europace. 2005;7:353-65.

2. Fetter J, Aram G, Holmes DR, Gray JE, Hayes DL. The effects of nuclear magnetic resonance imagers on external and implantable pulse generators. Pacing Clin Electrophysiol. 1984;7:720-7.

3. Duru F, Luechinger R, Scheidegger MB, Luscher TF, Boesiger P, Candinas R. Pacing in magnetic resonance imaging environment: clinical and technical considerations on compatibility. Eur Heart J. 2001;22:113-24.

4. Vahlhaus C, Sommer T, Lewalter T, et al. Interference with cardiac pacemakers by magnetic resonance imaging: are there irreversible changes at 0.5T? Pacing Clin Electrophysiol. 2001;24:489-95.

5. Wilkoff BL, Bello D, Taborsky M, Vymazal J, Kanal E, Heuer H, et al. Magnetic resonance imaging in patients with a pacemaker system designed for the magnetic resonance environment. Heart Rhythm. 2011;8:65-73.

6. Elmouchi DA, Rosema S, Vanoosterhout SM, Khan M, Davis AT, Gauri AJ, et al. Cardiac perforation and lead dislodgement after implantation of a MR-conditional pacing lead: a single center experience. Pacing Clin Electrophysiol. 2014;37:4-10.
7. Shenthar J, Milasinovic G, Al Fagih A, Götte M, Engel G, Wolff S, et al. MRI scanning in patients with new and existing CapSureFix Novus 5076 pacemaker leads: randomized trial results. Heart Rhythm. 2015;12:759-65 https://doi.org/10.1016/j.hrthm.2014.12. 035 .

8. Higgins JV, Gard JJ, Sheldon SH, Espinosa RE, Wood CP, Felmlee JP, et al. Safety and outcomes of magnetic resonance imaging in patients with abandoned pacemaker and defibrillator leads. Pacing Clin Electrophysiol. 2014;37:1284-90.

9. Ferreira AM, Costa F, Tralhão A, Marques H, Cardim N, Adragão P. MRI-conditional pacemakers: current perspectives. Medical Devices: Evidence and Research. 2014;7:115-24.

10. Miller JD, Nazarian S, Halperin HR. Implantable electronic cardiac devices and compatibility with magnetic resonance imaging. J Am Coll Cardiol. 2016;68:1590-8.

11. Indik JH, Gimbel JR, Abe H, Alkmim-Teixeira R, BirgersdotterGreen U, Clarke GD, et al. HRS expert consensus statement on magnetic resonance imaging and radiation exposure in patients with cardiovascular implantable electronic devices. Heart Rhythm. 2017;14:e97-e153 https://doi.org/10.1016/j.hrthm.2017.04.025.

12. Brignole $\mathrm{M}$, Auricchio A, Baron-Esquivias G, Bordachar P, Boriani G, Breithardt OA, et al. 2013 ESC guidelines on cardiac pacing and cardiac resynchronization therapy: the task force on cardiac pacing and resynchronization therapy of the European Society of Cardiology (ESC). Europace. 2013;15:1070-118.

13. Russo RJ, Costa HS, Silva PD, Anderson JL, Arshad A, Biederman RWW, et al. Assessing the risks associated with MRI in patients with a pacemaker or defibrillator. N Engl J Med. 2017;376:755-64.

14. Do DH, Eyvazian V, Bayoneta AJ, Hu P, Finn JP, Bradfield JS, et al. Cardiac magnetic resonance imaging using wideband sequences in patients with nonconditional cardiac implanted electronic devices. Heart Rhythm. 2018;15:218-25.

15. Padmanabhan D, Kella DK, Mehta R, Kapa S, Deshmukh A, Mulpuru S, et al. Safety of magnetic resonance imaging in patients with legacy pacemakers and defibrillators and abandoned leads. Heart Rhythm. 2018;15:228-33.

16. Nazarian SM, Hansford R, Rahsepar AA, Weltin V, McVeigh D, Ipek EG, et al. Safety of magnetic resonance imaging in patients with cardiac devices. N Engl J Med. 2017;377:2555-64.

17. Shah AD, Morris MA, Hirsh DS, Warnock M, Huang Y, Mollerus $\mathrm{M}$, et al. Magnetic resonance imaging safety in nonconditional pacemaker and defibrillator recipients: a meta-analysis and systematic review. Heart Rhythm. 2018;15:1001-8.

18. CMS.gov April 10 2018: https://www.cms.gov/medicare-coveragedatabase/details/nca-decision-memo.aspx?NCAId=289

19. British Cardiovascular Society and Royal College of Radiologists joint statement on MRI for patients with pacemakers and implantable cardioverter defibrillators MRI conditional and legacy devices. 2018 August 10. www.bcs.com 